\title{
Gastric metaplasia and duodenal ulcer disease in children infected by Helicobacter pylori
}

\author{
S M Gormally, B M Kierce, L E Daly, B Bourke, R Carroll, M T Durnin, B Drumm
}

\begin{abstract}
Background-Helicobacter pylori infection of the gastric mucosa is vital in the pathogenesis of duodenal ulcer disease. $H$ pylori will only colonise gastric epithelium and its association with duodenal disease is therefore not easily explained. Aims-To determine if gastric metaplasia in the duodenum increases the risk of duodenal ulcer disease in children infected with $\mathrm{H}$ pylori.
\end{abstract}

Patients-All children undergoing upper endoscopy over a 20 month period in a children's hospital in Ireland.

Methods-Two biopsy specimens were obtained from the antral mucosa and two from the first part of the duodenum. One antral biopsy specimen was used in a rapid urease test (Clo Test). Biopsy sections were stained with haematoxylin and eosin and also with cresyl violet for identification of $\boldsymbol{H}$ pylori. Periodic acid Schiff (PAS) stain was performed to identify areas of gastric metaplasia.

Results-Gastric and duodenal biopsy specimens were obtained from 148 patients (M:F 1·2:1). Twenty five children (17\%) had $H$ pylori positive gastritis. Thirty four children (23\%) had gastric metaplasia in the duodenum. Nine per cent of children under the age of 8 years had gastric metaplasia compared with $38 \%$ in those 12 years of age or over $(p<0 \cdot 005)$. Seven children had duodenal ulcer disease. Gastric metaplasia was present in six of seven $(86 \%)$ children with duodenal ulcer disease compared with 28 of $141(20 \%)$ without ulceration $(p<0 \cdot 001)$. While both $H$ pylori and gastric metaplasia were each significant risk factors for duodenal ulcer disease, the combined presence of both factors was associated with a pronounced increase in duodenal ulcer disease. Duodenal ulcer disease occurred in over $50 \%$ of children with both $H$ pylori infection and gastric metaplasia. In contrast duodenal disease did not occur in children ( 0 of 100) when both were absent.

Conclusion-The presence of gastric metaplasia in the duodenum is the major risk factor for duodenal ulcer disease in patients colonised by $\boldsymbol{H}$ pylori.

(Gut 1996; 38: 513-517)

Keywords: Helicobacter pylori, gastric metaplasia, gastritis, duodenal ulcer disease.

Helicobacter pylori is a Gram negative spiral organism that colonises the gastric mucosa of humans. $H$ pylori is the major cause of gastritis in children and adults. ${ }^{1-6}$. There is a strong association between $H$ pylori gastritis and duodenal ulcer disease. ${ }^{78}$ Duodenal ulceration does not recur if $H$ pylori is cured. ${ }^{7-9}$ It is not known why $H$ pylori, which will only colonise gastric tissue, has such a profound effect on the natural history of duodenal ulcer disease. There is speculation that $H$ pylori colonises the gastric mucosa and subsequently colonises areas of gastric metaplasia in the duodenum leading to erosions and ulceration. ${ }^{10}$ To date, no prospective study has shown an association between $H$ pylori gastritis, gastric metaplasia of the duodenum, and duodenal ulcer disease. The hypothesis is difficult to prove in an adult population because there is a significant prevalence of chronic gastritis, gastric metaplasia in the duodenum, and duodenal ulcer disease among this age group. In contrast $H$ pylori gastritis and duodenal ulceration are uncommon among children in developed countries. Children therefore represent an excellent population in which to study the relation between $H$ pylori infection, gastritis, gastric metaplasia in the duodenum, and duodenal disease.

This study was carried out prospectively to discover if an association existed between $H$ pylori colonisation of the gastric mucosa, the occurrence of gastric metaplasia in the duodenum, and duodenal ulcer disease.

\section{Methods}

Patients

One hundred and ninety three children underwent upper endoscopic examination over a 20 month period. Table I outlines the indications for endoscopy. During each examination, two biopsy specimens were obtained from the first part of the duodenum. A further two samples were taken from the antral mucosa, one of which was used for a rapid urease test (Clo, Delta West)

Forty five children were excluded from further study either because the biopsy specimens were unsuitable $(n=11)$ or because a full complement of specimens were not obtained $(n=34)$. The ages of those children excluded ranged from 0.25 to 15.5 years (mean (SD) age $5 \cdot 8(5 \cdot 1))$. The remaining 148 patients ranging in age from 0.3 to 17.7 (mean (SD) age 8.8 $(4 \cdot 6)$ ) were entered in the study. The male to female ratio was $1 \cdot 2: 1$. One patient had a history of alcohol consumption whereas no patient admitted to smoking. None of the children were taking non-steroidal anti-inflammatory drugs. 
TABLE I Major indication for endoscopy

Small bowel biopsy Abdominal pain 92 53 Crohn's disease

Total 193

\section{Endoscopy}

Oesophagogastroduodenoscopy was performed under general anaesthetic in all children. An Olympus GIF X P10 or Q 200 endoscope (Keymed, Ireland) was used depending on the size of the child.

\section{Histological examination of biopsy specimens}

Gastric and duodenal biopsy specimens were fixed in $10 \%$ neutral formalin, embedded in paraffin wax, and cut at 5 microns. The sections were stained with haematoxylin and eosin for light microscopy.

\section{Gastric specimens}

Gastritis was defined according to established histological criteria using the Sydney classification. ${ }^{11}$ Three patterns of gastritis were looked for: chronic, acute, and special forms (for example, granulomas, eosinophilic infiltration). In chronic gastritis the predominant cell infiltrate consists of lymphocytes and plasma cells. These infiltrates were graded mild, moderate or severe. The morphology of chronic gastritis was further described using the following graded variables: (a) activity: the presence of neutrophil granulocytes in either or both the lamina propria and intraepithelial sites; (b) atrophy: the loss of gastric glands; (c) the presence of $H$ pylori; (d) the presence of intestinal metaplasia.

Acute gastritis was defined as a predominantly neutrophil infiltrate in either or both the lamina propria and intraepithelial sites.

Formalin fixed specimens were stained with cresyl violet to identify $H$ pylori. The organisms were easily identified because of their spiral or curved shape and their unique location beneath and within the mucous layer on the surface of the gastric mucosa. $H$ pylori colonisation was graded according to the numbers of organisms seen as mild, when occasional micro-organisms were present, moderate when there was a patchy distribution of bacteria, and severe if a layer of bacteria was present on the surface of the section. ${ }^{11}$

\section{Duodenal specimens}

Chronic non-specific duodenitis was defined according to Hasan et al. ${ }^{12}$ Duodenitis was characterised by the presence of neutrophils in the lamina propria, crypts or surface epithelium in addition to an increase in the number of mononuclear cells. Duodenitis was graded from mild to severe depending on the number of neutrophils present.

All duodenal biopsy specimens were stained with periodic acid Schiff reagent (PAS) stain to assist the identification of areas of gastric metaplasia. Gastric epithelium was defined as the presence of adjacent surface epithelial cells con- taining PAS positive neutral mucin. The extent of gastric metaplasia was graded on a scale from 1 to 3. When eight or less consecutive cells of gastric metaplasia were present in the duodenal epithelium, this was considered to be grade 1 . Grade 2 gastric metaplasia was present if islands of gastric metaplasia were scattered between areas of duodenal epithelium. In grade 3 , all the biopsy tissue showed changes of gastric metaplasia.

Cresyl violet staining was then used for $H$ pylori identification as with gastric biopsy sections.

All of the specimens were examined by a pathologist who was unaware of the clinical history, endoscopic findings or the urease test result.

\section{Statistics}

Results were expressed as mean (SD) or as relative risks. Differences between groups were compared using the $\chi^{2}$ test. Where there were small numbers in some categories, the two tailed Fisher's exact test was used. Confidence intervals for relative risk were based on a Taylor series expansion. ${ }^{13}$

\section{Results}

\section{GASTRITIS}

$H$ pylori colonisation of the gastric mucosa was confirmed by both the rapid urease test (Clo test) and cresyl violet stain in 25 children. All had histological evidence of chronic gastritis. Twenty four per cent had mild chronic gastritis, $36 \%$ moderate chronic gastritis, and $40 \%$ active chronic gastritis. Gastric atrophy and intestinal metaplasia were not identified in specimens from these children. $H$ pylori infection was graded mild to severe. Fifty six per cent $(n=14)$ of children had mild $H$ pylori infection with $40 \%$ $(\mathrm{n}=10)$ having moderate and $4 \%(\mathrm{n}=1)$ severe $H$ pylori infection respectively. The urease test and cresyl violet stain were both negative on specimens from each of the other 123 patients.

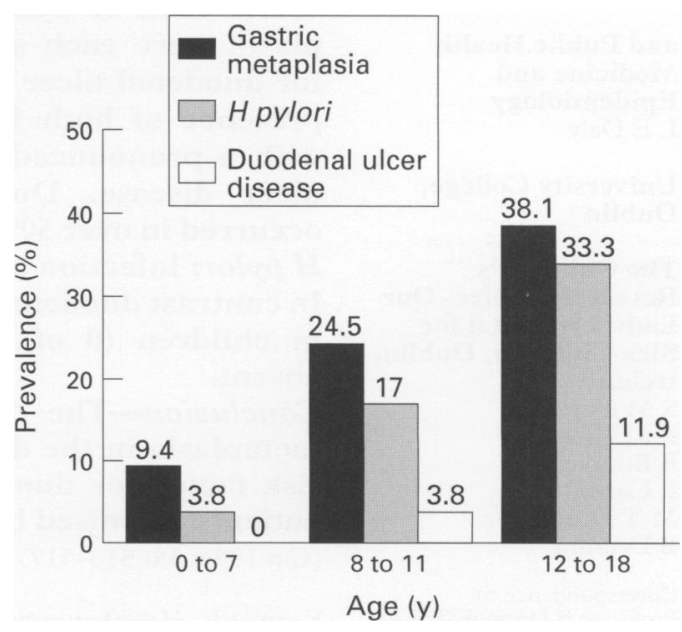

Relation between patients' ages, $\mathrm{H}$ pylori, gastric metaplasia, and duodenal disease. The prevalence of $\mathrm{H}$ pylori $\left(\chi^{2}=14.58, d f=2, p<0.01\right)$, gastric metaplasia $\left(\chi^{2}=10.99, d f=2, p<0.005\right)$, and duodenal ulcer disease $\left(\chi^{2}=7 \cdot 54, d f=2, p<0 \cdot 05\right)$, all increase with age. 
TABLE II Patients with duodenal ulcer disease

\begin{tabular}{llllll}
\hline Sex & Age & $\begin{array}{l}\text { Endoscopy } \\
\text { findings }\end{array}$ & Histology & $\begin{array}{l}\text { H pylori on } \\
\text { gastric mucosa }\end{array}$ & $\begin{array}{l}\text { Gastric } \\
\text { metaplasia }\end{array}$ \\
\hline M & $13 \cdot 1$ & Duodenal ulcer & Normal & Moderate & Grade 2 \\
M & $14 \cdot 2$ & Duodenal ulcer & Severe duodenitis & Moderate & Grade 3 \\
M & 14 & Duodenal ulcer & Severe duodenitis & Mild & Absent \\
M & $13 \cdot 1$ & Duodenal ulcer & Acute duodenitis & Mild & Grade 3 \\
F & $11 \cdot 6$ & Duodenal ulcer & Acute duodenitis & Moderate & Grade 2 \\
F & $11 \cdot 7$ & Duodenal ulcer & Severe duodenitis & Mild & Grade 2 \\
F & 12 & Duodenal ulcer & Normal & Moderate & Grade 2 \\
\hline
\end{tabular}

The M:F ratio of children with $H$ pylori gastritis was 1.8:1. Ages ranged from $3 \cdot 8$ to 16 years (mean (SD) $11.7(2 \cdot 87)$ ). The prevalence of $H$ pylori infection increased with age (Figure). Four per cent (two of 53) of children between 0 and 7 years of age had $H$ pylori. This contrasted with prevalence of $17 \%$ (nine of 53) and $33 \%$ (14 of 42 ) in the 8-11 year old and 12-18 year old age groups respectively $\left(\chi^{2}=14 \cdot 58, \mathrm{df}=2, \mathrm{p}<0.001\right)$.

\section{GASTRIC METAPLASIA}

Gastric metaplasia in the duodenum was present in 34 of $148(23 \%)$ patients. Children with gastric metaplasia ranged from 1 to 17 years of age (mean (SD) age 11.1 (3.39)). Twenty nine of these 34 children $(85 \%)$ had grade 2 gastric metaplasia. In contrast only two children $(6 \%)$ had grade 1 gastric metaplasia and three $(9 \%)$ had grade 3 gastric metaplasia.

The prevalence of gastric metaplasia increased with age (Figure). Nine per cent (five of 53) of children under 8 years had evidence of gastric metaplasia. In contrast, $25 \%$ (13 of 53) of patients between 8 and 11 years and $38 \%$ (16 of 42 ) of patients who were 12 years or more, were found to have metaplasia $\left(\chi^{2}=10.99, \mathrm{df}=2, \mathrm{p}<0.005\right)$. Gastric metaplasia occurred equally in both sexes (M:F ratio $1 \cdot 2: 1$ ).

\section{Gastric metaplasia and gastritis}

Gastric metaplasia was associated with $H$ pylori colonisation of the gastric mucosa. Eleven of $34(32 \%)$ patients with gastric metaplasia had $H$ pylori present on the gastric mucosa. Fifty five per cent had mild $H$ pylori colonisation and $45 \%$ moderate. In contrast, 14 of $114(12 \%)$ patients who did not have gastric metaplasia were colonised with $H$ pylori $\left(\chi^{2}=7.52 \mathrm{df}=1\right.$, $\mathrm{p}<0.01)$.

TABLE III The association between gastric metaplasia, gastritis, $\mathrm{H}$ pylori infection, and duodenal ulcer disease

\begin{tabular}{|c|c|c|c|c|}
\hline & \multirow[b]{2}{*}{ Number } & \multicolumn{3}{|c|}{ Duodenal ulcer disease } \\
\hline & & $\begin{array}{l}\text { Prevalence } \\
(\%)\end{array}$ & $\begin{array}{l}\text { Relative risk } \\
(95 \% C I)\end{array}$ & p Value \\
\hline $\begin{array}{l}H \text { pylori } \\
\text { Present } \\
\text { Absent }\end{array}$ & $\begin{array}{r}25 \\
123\end{array}$ & $\begin{array}{l}7(28) \\
1(0)\end{array}$ & $\star$ & $<0.0001$ \\
\hline $\begin{array}{l}\text { Gastric metaplasia } \\
\text { Present } \\
\text { Absent } \\
\text { H pylori present }\end{array}$ & $\begin{array}{r}34 \\
114\end{array}$ & $\begin{array}{l}6(17 \cdot 6) \\
1(0 \cdot 9)\end{array}$ & $20 \cdot 1(2.5$ to 161.4$)$ & $<0.001$ \\
\hline $\begin{array}{l}\text { Gastric metaplasia present } \\
\text { Gastric metaplasia absent } \\
H \text { pylori absent } \\
\text { Gastric metaplasia present } \\
\text { Gastric metaplasia absent }\end{array}$ & $\begin{array}{r}23 \\
100\end{array}$ & $\begin{array}{l}6(54 \cdot 5) \\
1(7 \cdot 1) \\
0(0) \\
0(0)\end{array}$ & $\begin{array}{l}7.6(1 \cdot 1 \text { to } 54 \cdot 4) \\
1.0\end{array}$ & $<0.01$ \\
\hline
\end{tabular}

*Undefined because of zero cases.
DUODENAL ULCER DISEASE

Duodenal disease was present in only nine patients. Seven of these children had duodenal ulceration, five of whom had acute or severe chronic duodenitis (Table II). Two children who had a normal endoscopic appearance of the duodenum, were found to have moderate duodenitis on histological examination. Patients with duodenal ulcer disease ranged in age from 11.6 to 14.2 years (mean (SD) age $12.8(1.07))$. The prevalence of ulcer disease increased with age (Figure). Duodenal ulcer disease did not occur in children under 8 years of age. Four per cent (two of 53) of children between 8 and 11 years had duodenal ulceration compared with $12 \%$ (five of 42 ) of children who were 12 years or more $\left(\left(\chi^{2}=7 \cdot 54\right.\right.$, $\mathrm{df}=2, \mathrm{p}<0.05)$. Duodenal biopsy specimens obtained from the remaining 139 children showed no evidence of inflammation.

\section{$\mathrm{H}$ pylori gastric metaplasia, and duodenal ulcer} disease

$H$ pylori colonisation of the gastric mucosa and gastric metaplasia in the duodenum were major risk factors for duodenal ulcer disease. Seven of 25 children with $H$ pylori colonisation of the gastric mucosa had duodenal ulcer disease. In contrast none of the 123 children who were not colonised with $H$ pylori had duodenal ulceration $(p<0.001)$ (Table III). The risk of duodenal ulcer disease in children colonised by $H$ pylori was greatly decreased if gastric metaplasia was absent. Duodenal ulcer disease occurred in only one of $14(7 \cdot 1 \%)$ children colonised by $H$ pylori when gastric metaplasia was not identified (Table III).

Thirty four children had gastric metaplasia and of these six had duodenal ulcer disease compared with only one of 114 children who did not have gastric metaplasia $(p<0.001)$. The relative risk of duodenal ulcer disease among children with gastric metaplasia was 20.1 compared with those without gastric metaplasia (Table III). However, duodenal ulcer disease did not occur in children with gastric metaplasia if $H$ pylori was not present on the gastric mucosa.

If both $H$ pylori colonisation of the antral mucosa and gastric metaplasia in the duodenum were present in a child, the prevalence of duodenal ulcer disease was over $50 \%$ (Table III). In contrast when both $H$ pylori and gastric metaplasia were absent $(n=100)$ duodenal ulcer disease never occurred.

\section{Discussion}

This is, to our knowledge, the first prospectively carried out study among adults or children examining the relation between $H$ pylor gastritis, gastric metaplasia in the duodenum, and duodenal ulcer disease. $H$ pylori colonisation of the gastric mucosa plays a critical part in the pathogenesis of duodenal ulcer disease. Eradication of $H$ pylori results in longterm healing of duodenal ulcers. ${ }^{7-9} 1415$ Duodenal ulceration recurs if there is persistent or recurrent infection of the gastric mucosa by 
H pylori. ${ }^{7-9} 1415$ It is not known why a bacterial infection of the antral mucosa is critical in the pathogenesis of ulcers that occur in the duodenum. It has been hypothesised that $H$ pylori colonises areas of gastric metaplasia in the duodenum with the subsequent development of duodenal inflammation and possibly ulceration. ${ }^{10}$ It is difficult for studies of adult patients to establish a relation between $H$ pylori infection, gastric metaplasia, and duodenal ulcer disease because of the comparatively high prevalence of $H$ pylori colonisation and duodenal ulcer disease among adults. In contrast children present an ideal group in whom to examine this association. In developed countries both $H$ pylori colonisation of the gastric mucosa and duodenal ulcer disease are uncommon in children. 56 16-20

This study shows that the presence of gastric metaplasia in the duodenum is the major risk factor for the development of duodenal ulcer disease in children colonised by $H$ pylori. $H$ pylori infection of the antral mucosa and gastric metaplasia in the duodenum were each risk factors for duodenal ulceration and inflammation. The presence of $H$ pylori on the antral mucosa in the absence of gastric metaplasia in the duodenum, however, was associated with duodenal disease in only one child. In contrast the presence of both $H$ pylori and gastric metaplasia together resulted in a remarkable increase in the risk of duodenal disease.

When duodenal ulceration occurs in children the clinical course is identical to that seen in adult patients. Children have chronic symptoms and ulcers usually recur after stopping treatment with histamine receptor blocking agents. ${ }^{19-22}$ The prevalence of duodenal ulcer disease increases progressively with age. It is extremely unusual for primary duodenal ulceration to occur under 10 years of age. ${ }^{19} 20$ In this study we found that the prevalence of $H$ pylori colonisation and gastric metaplasia each increased progressively with age. The previously unexplained absence of primary ulceration in very young children is probably because of the very low prevalence of gastric metaplasia and $H$ pylori in this age group.

There is a high prevalence of $H$ pylori infection among children in underdeveloped countries. ${ }^{23-25}$ Unfortunately the prevalence of duodenal ulcer disease among these children is unknown. In Canada, Hassall and Dimmick have shown that both $H$ pylori infection and duodenal ulcer disease are much more common among North American Indian children than among white children. ${ }^{26}$ Furthermore duodenal ulcers generally occurred in native Indian children when they were over 9 years old. The incidence of duodenal ulceration among adolescents might therefore approach adult levels if $H$ pylori infection was more prevalent in young children as gastric metaplasia seems to be comparatively common in teenagers.

Gastric metaplasia has not previously been examined prospectively in children. Two specimens were obtained from the first part of the duodenum in an effort to identify most children with gastric metaplasia. Wyatt et al have shown that a single duodenal biopsy specimen identifies metaplasia in only $63 \%$ of patients in whom gastric metaplasia is identified if multiple specimens are taken, while two duodenal specimens are successful in identifying metaplasia in $94 \%$ of such patients. ${ }^{27} \mathrm{We}$ found gastric metaplasia in a high proportion of teenagers. A previous retrospective study of biopsy specimens obtained from Canadian children found gastric metaplasia in $42 \%$ of $H$ pylori colonised children. ${ }^{28}$ The low incidence of metaplasia in the under 10 year old age group suggests that gastric metaplasia is not congenital in origin. One of the factors promoting the development of metaplasia with increasing age seems to be the presence of gastritis. Wyatt et al found a similar association between gastritis and the prevalence of gastric metaplasia in adults. ${ }^{27} 29$ Other factors, however, must be important in promoting the development of gastric metaplasia as gastric metaplasia in the duodenum did occur in the absence of $H$ pylori colonisation.

In this study gastric metaplasia was identified in $89 \%$ of children with duodenal inflammation. A possible association between duodenitis and gastric metaplasia has previously been suggested in adults. ${ }^{30}$ More recently Wyatt et al have confirmed an association between $H$ pylori infection, gastric metaplasia in the duodenum, and the presence of duodenitis. ${ }^{27} 29$ In their study, active duodenitis was rarely seen in the absence of gastric metaplasia. Carrick et al reviewed their experience of gastric metaplasia and found that $90 \%$ of patients with active duodenal ulceration or a previous history of duodenal ulcer disease had gastric metaplasia. ${ }^{31}$ In contrast only $30 \%$ of the population who do not have a history of duodenal ulceration have metaplasia. It seems therefore that gastric metaplasia is an important factor in the development of active duodenitis even in the absence of frank ulceration.

In summary our findings show that the coexistence of gastric metaplasia in the duodenum and $H$ pylori colonisation of the antral mucosa is critical for the development of duodenal ulcer disease in children. Further studies are required to determine the significance of $H$ pylori colonisation in promoting the development of gastric metaplasia.

1 Marshall BJ, Warren JR. Unidentified curved bacilli in the stomach of patients with gastritis and peptic ulceration Lancet 1984; i: 1311-5.

2 Dooley CP, Cohen $H$. The clinical significance of Campylobacter pylori. Ann Intern Med 1988; 108: 70-9.

3 Blaser MJ. Epidemiology and pathophysiology of Campylobacter pylori infections. Rev Infect Dis 1990; 99-106.

4 Peterson WL. Helicobacter pylori and peptic ulcer disease. $N$ Engl f Med 1991; 324: 1043-8.

5 Drumm B, Sherman P, Cutz E, Karmali M. Association of Campylobacter pylori on the gastric mucosa with antral gastritis in children. N Engl f Med 1987; 316: 1557-61. 6 Drumm B, Perez-Perez GI, Blaser MJ, Sherman PM. Intrafamilial clustering of Helicobacter pylori infection. $N$ Engl f Med 1990; 322: 359-63.

7 Hentschel E, Brandstatter G, Dragosics B, Hirschl AM, Nemec $\mathrm{H}$, Schutze $\mathrm{K}$, et al. Effect of ranitidine and amoxycillin plus metronidazole on the eradication of Helicobacter pylori and the recurrence of duodenal ulcer. $N$ Engl F Med 1993; 328: 308-12.

8 Graham DY. Treatment of peptic ulcers caused by Helicobacter pylori. N Engl f Med 1993; 328: 349-50.

9 Graham DY, Lew GM, Klein PD, Evans DG, Evans DJ Jr, Saeed SA, et al. Effect of treatment on the long term recurrence of gastric or duodenal ulcer. A randomized, controlled study. Ann Intern Med 1992; 116: 705-8. 
10 Goodwin CS: Duodenal ulcer, Campylobacter pylori and the 'leaking roof' concept. Lancet 1988; ii: 1467-9.

11 Price AB. The Sydney system: histological division. $f$ Gastroenterol Hepatol 1991; 6: 209-22.

12 Hasan M, Sircus W, Ferguson A. Duodenal mucosal architecture in non-specific and ulcer associated duodenitis. Gut 1981; 22: 637-41.

13 Greenland S, Robins JM. Estimation of a common effect parameter from sparse follow-up data. Biometrics 1985; 41: 55-68.

14 Marshall BJ, Goodwin CS, Warren JR, Murray R, Blincow E, Blackbourn S, et al. Prospective double-blind trial of duodenal ulcer relapse after eradication of Campylobacter pylori. Lancet 1988; ii: 1437-41.

15 Coughlan JG, Gilligan D, Humphries H, McKenna D, Dooley C, Sweeney E, et al. Campylobacter pylori and Dooley C, Sweeney E, et al. Campylobacter pylori and
recurrence of duodenal ulcers - a 12 month follow up recurrence of duodenal ulcers -

16 Drumm B, O'Brien A, Cutz E, Sherman P. Campylobacter pyloridis associated primary gastritis in children. Pediatrics 1987; 80: 192-5.

17 Drumm B. Helicobacter pylori. Arch Dis Child 1990; 65: 1278-82.

18 Czinn SJ, Carr HS, Speck WT. Diagnosis of gastritis caused by Helicobacter pylori in children by means of an ELISA. Rev Infect Dis 1991; 13: 700-3.

19 Drumm B, Rhoads JM, Stringer DA, Sherman PM, Ellis LE, Durie PR. Peptic ulcer disease in children: etiology, clinical findings and clinical course. Pediatrics 1988; 82: 410-4.

20 Murphy MS, Eastham EJ, Jimenez M, Nelson R, Jackson RH. Duodenal ulceration: review of 110 cases. Arch Dis RH. Duodenal ulceration:

21 Puri P, Boyd E, Blake N, Guiney EJ. Duodenal ulcer in childhood: a continuing disease in adult life. $\mathcal{F}$ Pediatr Surg 1978; 13: 525-6.
22 Murphy MS, Eastham EJ. Peptic ulcer disease in childhood: long-term prognosis. F Pediatr Gastroenterol Nutr 1987; 6: long-term.

23 Graham DY, Adam E, Reddy GT, Agarwal JP, Agarwal R, Evans DJ Jr, et al. Seroepidemiology of Helicobacter pylori infection in India. Comparison of developing and developed countries. Dig Dis Sci 1991; 36: 1084-8.

24 Megraud F, Brassens-Rabbe MP, Denis F, Belbouri A, Hoa DQ. Seroepidemiology of Campylobacter pylori infection in various populations. $f$ Clin Microbiol 1989; 27: $1870-3$.

25 Perez-Perez GI, Taylor DN, Bodhidatta L, Wongsrichanalai J, Baze WB, Dunn BE, et al. Seroprevalence of Helicobacter pylori infections in Thailand. F Infect Dis 1990; 161: 1237-41.

26 Hassall E, Dimmick JE. Unique features of Helicobacter pylori disease in children. Dig Dis Sci 1991; 36: 417-23. 27 Wyatt JI, Rathbone BJ, Sobala GM, Shallcross T, Heatley $\mathrm{RV}$, Axon ATR, et al. Gastric epithelium in the duodenum: its association with Helicobacter pylori and inflammation. F Clin Pathol 1990; 43: 981-6.

28 Shabib S, Cutz E, Drumm B, Sherman P. Helicobacter pylori infection is associated with gastric metaplasia in the duodenum. Gastroenterology 1992; 102 (suppl): A163.

29 Wyatt JI, Rathbone BJ, Dixon MF, Heatley RV. Campylobacter pyloridis and acid induced gastric metaplasia in the pathogenesis of duodenitis. F Clin Pathol 1987; 40: 841-8.

30 Kreuning J, Bosman FT, Kuiper G, vd Wal AM, Lindeman J. Gastric and duodenal mucosa in 'healthy' individuals. 31: 69-77.

31 Carrick J, Lee A, Hazell S, Ralston M, Daskalopoulos G. Campylobacter pylori, duodenal ulcer, and gastric metaplasia: possible role of functional heteropic tissue in ulcerogenesis. Gut 1989; 30: 790-7. 